ИЗВЕСТИЯ АКАДЕМИИ НАУК ЭСТОНСКОН ССР. ТОМ VI СЕРИЯ БНОЛОГИЧЕСКАЯ. 1957, № 3

\title{
MIKROBIOLOOGILISTEST PROTSESSIDEST MULLAS VALGE MESIKA KASVATAMISEL
}

\section{LASTING}

Valget mesikat kasutatakse Eesti NSV-s laialdaselt haljasväetisena ja söödakultuurina. Iga aastaga laieneb tema kasvupind. Seetōttu vajavad lahendamist küsimused mullaviljakuse muutustest mesika kasvatamisel.

Taimede mōju on üheks määravaks teguriks mulla mikrofloora arenemisele ja mullaviljakusele. Eriti suur tähtsus mullaviljakuse taastamisel on liblikōielistel taimedel. Russeli [ $\left.{ }^{16}\right]$ ja Kaila [ $\left.{ }^{4}\right]$ andmetel avaldavad üheaastased liblikōielised mullaviljakusele mōju ainult jărgneval aastal, mitmeaastaste liblikõieliste - ristiku, lutserni ja mesika - môju kestab aga kauem. Valge mesikas, tistik ja lutsern suurendavad nii neile järgnevate teraviljade saake kui ka lämmastikusisaldust mullas. Oheaastased liblikōielised aga, kuigi nad samuti suurendavad järgnevate teraviljade saake, muudavad lämmastikubilansi külvikorras negatiivseks $\left.{ }^{16}\right]$.

Meleško [15] väidab, et mesikas on eelviljana kõrge väärtusega. Ka Haller $\left[{ }^{1,3}\right]$ leiab, et juba mesika kasvu ajal tõuseb mullaviljakus ja mesikas ei ole mitte halvem struktuurimoodustaja kui põldhein.

Kaila $\left[{ }^{4}\right]$ arvates põhjustab liblikõieliste taimede suuremat mōju mullastruktuuristumisele risosfääri mikroorganismide populatsiooni aktiivsus.

Afanasjeva $\left[{ }^{8}\right]$ määras bakterite arvu sinise lutserni ja ida-orasheina all ning leidis, et baktereid oli esimesel juhul enamasti rohkem kui viimasel. Eriti palju oli lutserni all tselluloosilagundajaid baktereid.

Thom ja Humfeld $\left[{ }^{7}\right]$ avastasid, et lutserni, rukki ja viki all suureneb bakterite hulk. Väiksemal määral kasvab mulla seente arv, aga üldse ei suurene kiirikseente hulk.

Mitme autori $\left[{ }^{7},{ }^{13}\right]$ andmetel toimuvad mikrobioloogilised protsessid mullas liblikōieliste all intensiivsemalt kui teiste taimede all, sest liblikōieliste juured on rohkem asustatud mikroorganismidega kui kõrreliste juured $\left.{ }^{13}\right]$.

Berjozova, Sain ja Rempe [ $\left.{ }^{11}\right]$, analüüsides punase ristiku ja timuti juurte mikrofloorat, leidsid, et ristiku juurtel asub baktereid mitukümmend korda rohkem kui timuti juurtel. Samuti on sinise lutserni juurtel baktereid rohkem kui hariliku aruheina juurtel. Ristik ja lutsern, kasvades koos kōrrelistega, suurendavad bakterite arvu ja muudavad mikrofloora liigilist koosseisu kõrreliste juurtel.

Russeli $\left.{ }^{16}\right]$ arvates on ristiku, mesika ja lutserni risosfäär asustatud palju tihedamalt mikroorganismidega kui teiste kultuurtaimede, sealhulgas ka liblikōieliste risosfäär.

Eespooltoodud seisukohtadest lähtudes hakati uurima mikrobioloogilisi protsesse mullas mesika all. Mullaproovid mikrobioloogiliseks analüüsiks vōeti Kuusiku katsebaasi katsepōldudelt ja ka mōnede kolhooside tootmispōldudelt. Et saada ettekujutust mikrobioloogilistest protsessidest mesika kasvu ajal, selleks vôrreldi mikrofloora arengut ning mikroorganismide hulka mullas nii mesika all kui ka ilma mesikata. Proovid vổeti alati kôrvutiasuvatelt katselappidelt vôi pölluosadelt. Mikrofloora arenemist vaadeldi füsioloogitiste gruppide kaupa, eraldi esimese ja teise aasta mesika all.

1953. aastal võeti kahel korral proove Kuusikul rajatud põldkatsetest. Esimesel korral - 26. juulil - ei olnud mikroorganismide arv mullas mesika all veel palju muutunud (tabel 1). Teisel korral aga oli bakterite hulk mesika all mullas suurem kui ilma mesikata. Eriti väärib tähelepanu nii bakterite üldhulga kui ka nitrifitseerijate bakterite arvu kasv mesika all.

Mulla mikroorganismide hulga kasvu mesika all täheldati ka teistes katsetes. 1955. aastal Kuusiku katsebaasi agrotehnika- ja agrokeemia-labora- 
tooriumi komplekskatsetest tehtud analüüsid näitasid eelkõige ammonifitseerijate ja nitrifitseerijate bakterite arvu kasvu mesika mõjul (tabel 2). Teise proovi ajal oli ka tselluloosilagundajaid baktereid mesika kasvukoha mullas rohkem kui odrapõllu mullas.

Tabel 1

Mikroorganismide hulk ühes grammis kuivas mullas esimese aasta mesika all (1953. aastal Kuusiku katsebaasis rajatud katse)

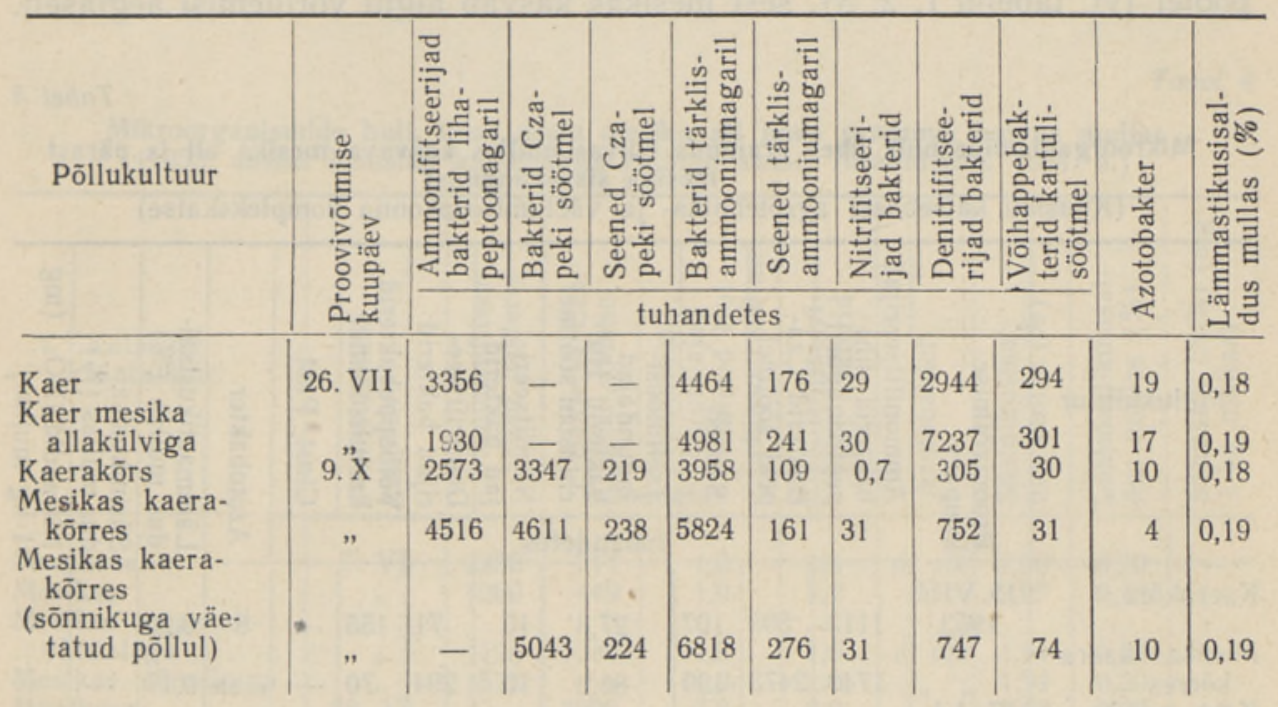

Eriti hästi ilmneb esimese aasta mesika mõju mulla mikrofloorale 1954. aastal Kuusikul korraldatud katses. 1953. aasta kevadel rajati katse kaerapõllul, kus ühele osale külvati aluskultuuriks mesikat, teisele mitte. Kuna mesikas oli sügiseks ebaühtlaselt arenenud, künti ta ümber. Järgmisel kevadel külvati mesikat uuesti kattevilja alla, kuid sellele ósale, kus teda eelmisel aastal ei olnud. Seega oli võimalik võrrelda sügisel sisseküntud esimese aasta mesika mõju (kuigi haljasmass oli väga väike) ja kasvava esimese aasta mesika mõju mulla mikrofloorale. Olukorda 1953. aastal iseloo-

Tabel 2

Mikroorganismide hulk ühes grammis kuivas mullas esimese aasta mesika all (Kuusiku katsebaasi agrotehnika- ja väetamisosakonna komplekskatse 1955. aastal)

\begin{tabular}{|c|c|c|c|c|c|c|c|c|c|c|c|}
\hline \multirow[t]{2}{*}{ Põllukultuur } & 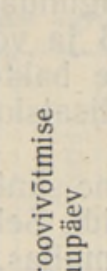 & 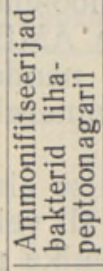 & 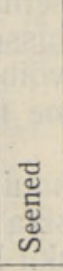 & 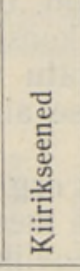 & 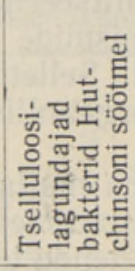 & 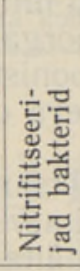 & 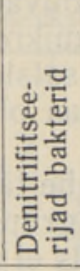 & 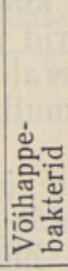 & \multirow[t]{2}{*}{ 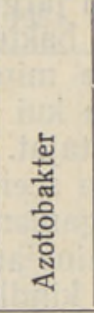 } & \multirow[t]{2}{*}{ 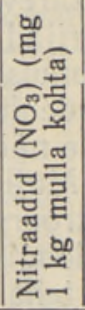 } & \multirow[t]{2}{*}{ 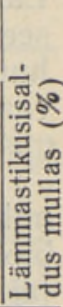 } \\
\hline & 호로 & \multicolumn{7}{|c|}{ tuhandetes } & & & \\
\hline $\begin{array}{l}\text { Oder } \\
\text { Oder mesika }\end{array}$ & 23. VI & 95 & 93 & 1112 & 3,1 & 0,3 & 311 & 311 & ei ole & 0,20 & 1,8 \\
\hline $\begin{array}{l}\text { all } \\
\text { Odra }\end{array}$ & $24 . "$ IX & $\begin{array}{r}443 \\
2980\end{array}$ & $\begin{array}{l}98 \\
97\end{array}$ & $\begin{array}{r}757 \\
4320\end{array}$ & $\begin{array}{l}2,1 \\
2,8\end{array}$ & $\begin{array}{l}2,9 \\
0,7\end{array}$ & $\begin{array}{l}291 \\
100\end{array}$ & $\begin{array}{r}70 \\
305\end{array}$ & $\begin{array}{l}250 \\
\text { ei ole }\end{array}$ & $\begin{array}{l}0,19 \\
0,18\end{array}$ & $\begin{array}{l}1,7 \\
2,0\end{array}$ \\
\hline $\begin{array}{l}\text { Mesikas o } \\
\text { kōrres }\end{array}$ & & 5480 & 131 & 3680 & 6,4 & 7,1 & 156 & 320 & 648 & 0,18 & 2,0 \\
\hline
\end{tabular}


mustab 15. augustil tehtud analüüs (tabel 3). Sealt näeme, et mesika all oli suurem ammonifitseerijate, sahharoos-nitraat(Czapeki)söötmel kasvavate ja tselluloosilagundajate bakterite hulk. Seal, kus mesikas sisse künti, oli järgmisel kevadel mikrobioloogiliste protsesside intensiivsus kõrgem kui sellel põlluosal, kuhu külvati mesikas kevadel. Sügise poole aga muutub mikrobioloogiline tegevus mullas mesika all aktiivsemaks. Paistab silma just ammonifitseerijate, nitrifitseerijate ja tselluloosilagundajate bakterite hulga suurenemine kasvava mesika all mullas, mis ilmneb selgesti alles suve teisel poolel (vt. tabelid 1, 2, 3), sest mesikas kasvab algul võrdlemisi aeglaselt.

Tabel 3

\section{Mikroorganismide hulk ühes grammis kuivas mullas kasvava mesika all ja pärast mesika sissekündmist}

(Kuusiku katsebaasi agrotehnika- ja väetamisosakonna komplekskatse)

\begin{tabular}{|c|c|c|c|c|c|c|c|c|c|c|c|c|c|}
\hline \multirow[t]{2}{*}{ Põllukultuur } & \multirow{2}{*}{ 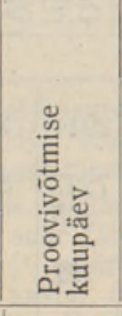 } & 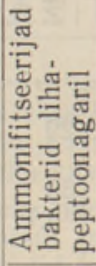 & 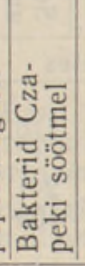 & 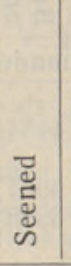 & 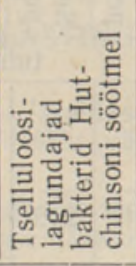 & 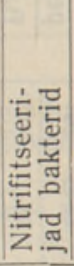 & 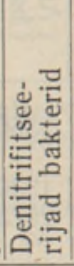 & 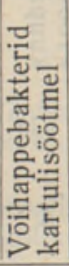 & $\begin{array}{l}\tilde{n} \\
\tilde{0} \\
0 \\
\dot{0} \\
0 \\
0\end{array}$ & \multirow[t]{2}{*}{ 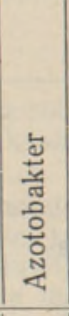 } & \multirow{2}{*}{\multicolumn{2}{|c|}{ 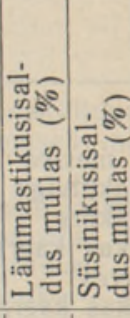 }} & \multirow[t]{2}{*}{ 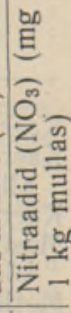 } \\
\hline & & \multicolumn{8}{|c|}{ tuhandetes } & & & & \\
\hline $\begin{array}{l}\text { Kaerakõrs } \\
\text { Mesikas kae }\end{array}$ & $\begin{array}{l}\text { 15. VIII } \\
1953\end{array}$ & 1113 & 598 & 107 & 27,8 & 10 & 71 & 155 & $\rightarrow$ & 8 & 0,20 & - & - \\
\hline $\begin{array}{l}\text { kōrres } \\
\text { Kaer mesika }\end{array}$ & 7." VI & 1743 & 2473 & 190 & 86,2 & 10 & 294 & 70 & - & ei ole & 0,17 & - & - \\
\hline allakülviga & 1954 & 1516 & 2757 & - & 10 & 10,6 & - & 74 & 740 & , & - & - & 一 \\
\hline $\begin{array}{l}\text { Kaer } \\
\text { Kaer mesika }\end{array}$ & 23."VI & 3011 & & & 10 & 50,8 & 一 & 88 & 740 & $"$ & & - & - \\
\hline $\begin{array}{l}\text { allakülviga } \\
\text { Kaer (sissekür }\end{array}$ & 1954 & & 4322 & - & 10,8 & & - & 68 & 680 & $"$ & 0,18 & 1,47 & 2,0 \\
\hline $\begin{array}{l}\text { tud mesikal) } \\
\text { Káer mesika }\end{array}$ & 31. VII & & 4242 & - & 6,2 & 10 & - & 74 & 740 & $"$ & 0,18 & 1,72 & 3,6 \\
\hline $\begin{array}{l}\text { allakülviga } \\
\text { Kaer (sissekün- }\end{array}$ & & 3178 & 3593 & 159 & 4,4 & - & 264 & 79 & 1000 & " & 0,19 & 1,94 & 5,4 \\
\hline $\begin{array}{l}\text { tud mesikal) } \\
\text { Mesikas kaera- }\end{array}$ & 30. V̈III & 1701 & 1719 & 132 & 3,244 & - & 330 & 79 & 1000 & " & 0,19 & 1,93 & 2,0 \\
\hline kōrres & 1954 & 4070 & & - & 4,2 & 34,3 & 822 & 82 & - & 一 & 0,17 & 1,77 & 3,6 \\
\hline $\begin{array}{l}\text { seküntud me- } \\
\text { sikal) }\end{array}$ & & 3480 & 2661 & & 1,0 & 3,3 & 80 & 80 & - & - & 0,16 & 1,68 & 3,8 \\
\hline
\end{tabular}

Lazarevi järgi kuuluvad nitrifitseerijad, tselluloosilagundajad ja ammonifitseerijad bakterid mikroorganismide kooslusse $\mathrm{AMB}$ ja vốtavad osa mulla huumuse mineralisatsioonist. Selletõttu võib nende bakterite arvu kasvu vaadelda kui mullas oleva orgaanilise aine mineralisatsiooni intensiivistumise näitajat.

Mulla seente, ühe tähtsama mulla orgaanilise aine sünteesist osavõtvate mikroorganismide grupi arv suureneb mesika all veidi. Selletõttu, et mikrobioloogiline analüüs ei näita nende tegelikku hulka mullas, ei saa selle põhjal teha kindlat järeldust mulla orgaanilise aine sünteesi intensiivistumise kohta.

Et valge mesika all ei arene intensiivselt ainult mineralisatsioon, vaid ka orgaanilise aine süntees, seda tõestab asjaolu, et valge mesika all ei ole nitraate kuigi palju rohkem kui mullas, kuhu mesikat pole külvatud.

Mikrobioloogilised protsessid mullas teise aasta mesika all kulgevad enamasti intensiivsemalt kui teiste taimede all. Tabelis 4 on võrreldud mikro- 
organismide hulka mustkesas ja mesika all. Mustkesas, kus toimub tugevdatud aeratsiooni tingimustes intensiivne orgaanilise aine mineralisatsioon, on just ammonifitseerijate bakterite hulk (sageli nimetatud ka bakterite üldhulgaks) peaaegu alati kõrgem kui mesika all, sest ammonifitseerijad bakterid on kōige arvukam mikroorganismide grupp. Bakterite hulk mesika all nendes variantides, mis said eelmisel aastal sõnnikut, ulatub küll peaaegu samale kõrgusele kui mustkesas, kuid protsessid kummalgi pool on tõenäoliselt erineva suunaga.

Tabel 4

Mikroorganismide hulk teise aasta mesika all ühes grammis kuivas mullas (1953. aastal Kuusiku katsebaasis rajatud katse. Analüüsitud 1954. a.)

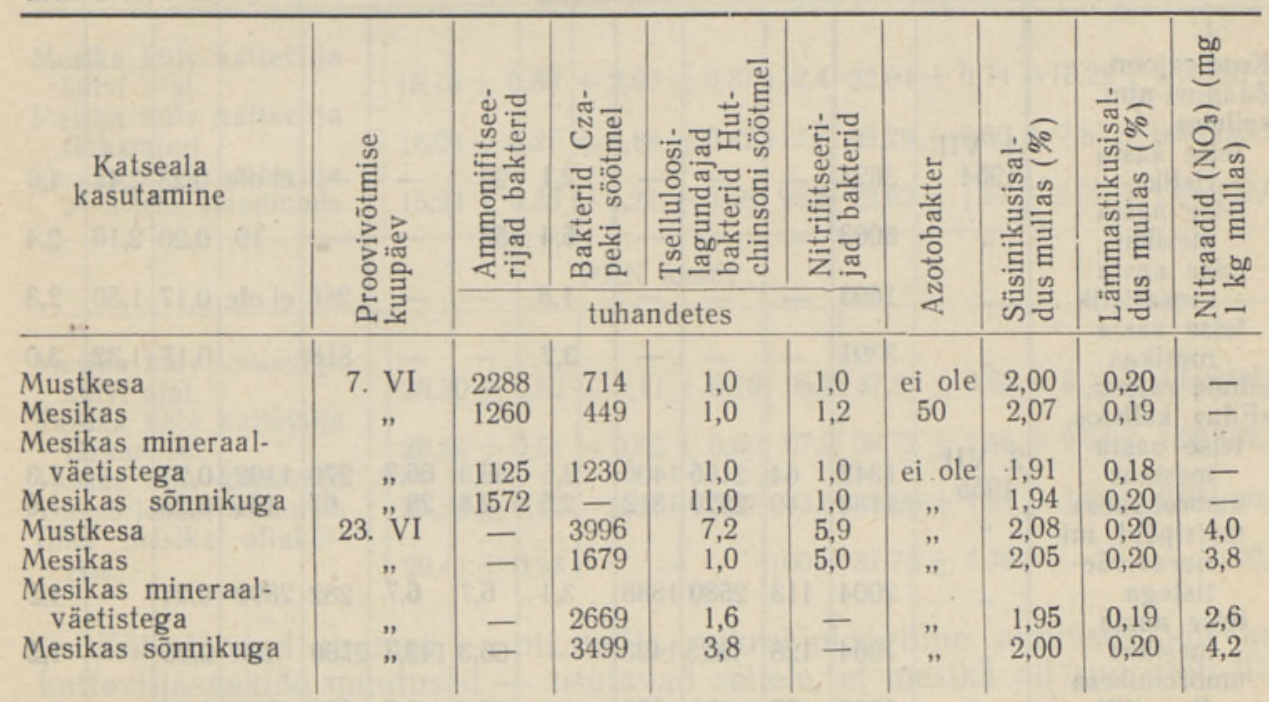

Mikroorganismide intensiivset arenemist teise aasta mesika all näitavad ka tabelis 5 toodud analüüsid. Sel juhul jääb mustkesa mikroorganismide aktiivsuselt isegi maha mesikakesast. Tselluloosilagundajaid mikroorganisme on mesika all mullas rökem. Võrreldes mustkesaga väärib erilist tähelepanu äärmiselt väike nitraatide hulk mesika all mullas.

Tabel 5

Mikroorganismide hulk teise aasta mesika all ühes grammis kuivas mullas (Kuusiku katsebaasi agrotehnika- ja väetamisosakonna komplekskatse 1954. aastal)

\begin{tabular}{|c|c|c|c|c|c|c|c|c|c|c|c|c|}
\hline \multirow[t]{2}{*}{$\begin{array}{l}\text { Katseala } \\
\text { kasutamine }\end{array}$} & \multirow[t]{2}{*}{ 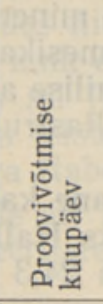 } & 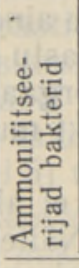 & $\begin{array}{l}\text { गू } \\
\text { पूँ } \\
\text { ஸ }\end{array}$ & 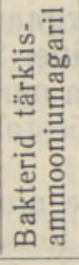 & 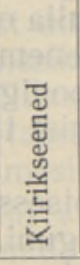 & 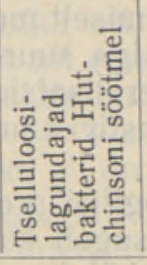 & 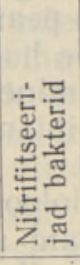 & 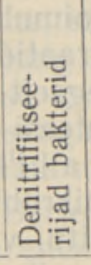 & 总: & \multirow{2}{*}{\multicolumn{2}{|c|}{ 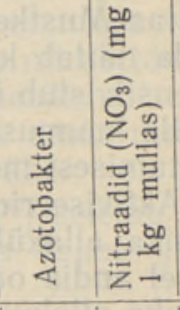 }} & \multirow[t]{2}{*}{ 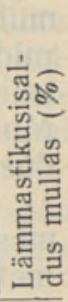 } \\
\hline & & & & , & tuh: & idetes & & & & & & \\
\hline $\begin{array}{l}\text { Mustkesa } \\
\text { Mesikas } \\
\text { Mustkesa } \\
\text { Mesikas }\end{array}$ & $\begin{array}{c}\text { 23. VI } \\
" \\
"\end{array}$ & $\begin{array}{l}369 \\
317 \\
237\end{array}$ & $\begin{array}{r}101 \\
121 \\
87 \\
83\end{array}$ & $\begin{array}{l}5620 \\
6010 \\
2870 \\
2230\end{array}$ & $\begin{array}{r}930 \\
682 \\
1010 \\
824\end{array}$ & $\begin{array}{l}0,9 \\
4,2 \\
1,2 \\
2,0\end{array}$ & $\begin{array}{l}7,1 \\
7,3 \\
0,3 \\
3,0\end{array}$ & $\begin{array}{l}297 \\
731 \\
312 \\
715\end{array}$ & $\begin{array}{r}297 \\
304 \\
750 \\
30\end{array}$ & $\begin{array}{c}\text { ei ole } \\
228 \\
\text { ei ole } \\
42\end{array}$ & $\begin{array}{r}10,4 \\
2,3 \\
6,6 \\
0,8\end{array}$ & $\begin{array}{l}0,19 \\
0,23 \\
0,16 \\
0,18\end{array}$ \\
\hline
\end{tabular}


Tabel 6

Mikroorganismide hulk mullas teise aasta mesika all kolhooside tootmispōldudel ühes grammis kuivas mullas

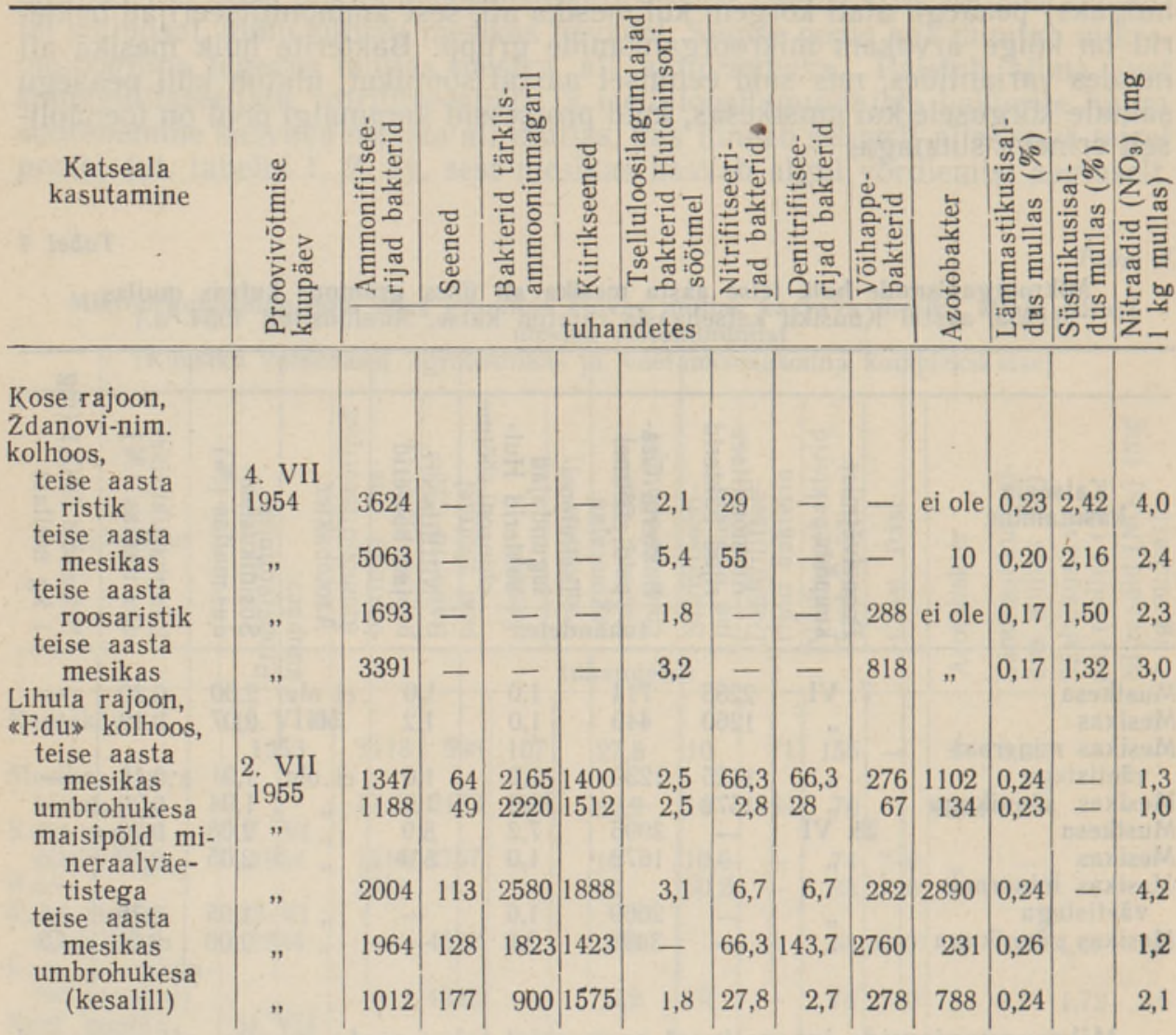

Mikroorganismide hulga kohta mullas teise aasta mesikapõldudel on toodud andmeid ka tabelis 6 . Siin võrreldakse mikroorganismide hulka mesika ja teiste taimede all mõnede kolhooside tootmispõldưdel. Neist andmetest näeme, et mikrobioloogilised protsessid kulgevad mesika all intensiivsemalt kui isegi teise aasta ristiku all. Nagu eelmistel juhtudel, suurenes siingi eelkõige ammonifitseerijate, tselluloosilagundajate ja nitrifitseerijate bakterite arv. Kõrge nitrifitseerijate bakterite sisaldus ilmneb Lihula rajooni «Edu» kolhoosi mesikapõldudelt võetud proovides. Väärib märkimist, et mustkesas on ammonifitseerijate bakterite hulk suurem, nitrifitseerijate ja tselluloosilagundajate bakterite hulk aga samasugune või isegi väiksem kui mesika all mullas. Mustkesas toimub peamiselt mulla orgaanilise aine mineralisatsioon, mida näitab ka nitraatide hulga suurenemine. Seevastu mesika all mullas intensiivistub üheaegselt mineralisatsiooniga mulla orgaanilise aine süntees. Mulla huumuse sünteesi intensiivistumist tõestab fakt mullastruktuuri moodustumisest mesika all [ $\left.{ }^{1}\right]$.

Aktiviseerides mikrobioloogilisi protsesse mullas ei alane katteviljasaak mesika allakülvi tõttu, vaid sageli koguni tõuseb. Näiteks Halleri [ ${ }^{3}$ ] andmetel andis oder mesika allakülviga 4 aasta keskmisena 24,3 ts/ha, ilma mesika allakülvita 23,4 ts/ha.

Mesika positiivne mõju katteviljasaagile ilmneb kõige selgemini fosforit ja kaaliumi sisaldavate mineraalväetiste foonil. Mineraalse lämmastikväetise kasutamisel aga ei ole allakülvatud mesikal positiivset mõju katteviljasaagile. Näitena võib tuua 1949, aastal E. Halleri poolt Kuusiku katsebaasis 
korraldatud katse andmed (tabel 7). Fosfor-kaaliumväetiste foonil vara kattevilja alla külvatud mesikas tõstis katteviljasaaki, fosfor-kaalium-lämmastikväetiste foonil aga veidi alandas.

Tabel 7

Katteviljaks külvatud kaera saagid erinevatel väetisfoonidel Kuusiku katsebaasis 1949. aastal

\begin{tabular}{c|c|c|c|c|c|c}
\hline \multirow{2}{*}{$\begin{array}{c}\text { Saak } \\
\text { ts/ha } \pm m\end{array}$} & $\begin{array}{c}\text { Enamsaak } \\
\text { ts/ha } \pm m\end{array}$ & $\%$ & $\begin{array}{c}\text { Saak } \\
\text { ts/ha } \pm m\end{array}$ & $\begin{array}{c}\text { Enamsaak } \\
\text { ts/ha } \pm m\end{array}$ & $\%$ \\
\cline { 2 - 6 } &
\end{tabular}

PK foonil

Mesika külv kattevilja külvi a'al

Mesika külv kattevilja tärkamisel

Mesika külv kattevilja $2-3$ lehe staadiumis

\begin{tabular}{|l|l|l|l|l|l}
$18,16 \pm 0,80+2,00 \pm 0,87$ & 112,4 & $32,64 \pm 0,74$ & $+15,22 \pm 6,96$ & 187,4 \\
$18,04 \pm 0,27$ & $+1,88 \pm 0,42$ & 111,7 & $25,29 \pm 0,69$ & $+7,87 \pm 0,88$ & 145,1 \\
$15,94 \pm 0,35$ & $-0,22 \pm 0,48$ & 98,6 & $22,62 \pm 1,57$ & $+5,20 \pm 1,66$ & 129,8
\end{tabular}

PKN foonil

Mesika külv kattevilja külvi ajal

Mesika külv kattevilja tärkamisel

Mesika külv kattevilja $2-3$ lehe staadiumis

Ilma mesika allakülvita

\begin{tabular}{|c|c|c|c|c|c}
$28,30 \pm 0,62$ & $-1,11 \pm 0,70$ & 96,2 & $37,89 \pm 0,66$ & $+0,11 \pm 1,50$ & 100,3 \\
$28,79 \pm 0,51$ & $-0,62 \pm 0,60$ & 97,9 & $38,72 \pm 1,46$ & $+0,94 \pm 1,99$ & 102,5 \\
$27,36 \pm 0,17$ & $-2,05 \pm 0,37$ & 93,0 & $36,26 \pm 1,81$ & $-1,52 \pm 2,25$ & 96,0 \\
$29,41 \pm 0,33$ & - & 100,0 & $37,78 \pm 1,35$ & - & 100,0
\end{tabular}

Kõik toodud andmed - nii mulla mikrobioloogiline aktiivsus kui ka katteviljasaakide mutused - osutavad sellele, et mesika all suureneb liikuva lämmastiku hulk mullas.

Kaila $\left[{ }^{4}\right]$ leidis, et herne, viki ja ristiku all suurenevad nii nitraatide hulk mullas kui ka mulla nitraatide kogumisvõime.* Need on liikuva lämmastiku sisalduse näitajateks mullas. Seejuures mitmeaastaste liblikõieliste (ristiku) mõjul suureneb liikuva lämmastiku sisaldus mullas tunduvalt rohkem kui üheaastaste mõjul. Vahe ilmnes kõige selgemini augustis, s. o. suve 1õpu poole. See on kooskõlas ka meie andmetega mikrobioloogilisest tegevusest mullas mesika all.

Afanasjeva $\left[{ }^{8}\right]$, võrreldes mulla mikrobioloogilist tegevust lutserni ja idaorasheina all, leidis, et lutserni all tõuseb mulla nitraatide kogumisvõime. Ta ei leidnud aga vahet nitraatidesisalduses ega nitrifitseerijate bakterite arvus lutserni ja ida-orasheina all.

Vaadeldes nitraatidesisaldust mesika all, näeme, et see on väga väike. Nitraatide hulk esimese aasta mesika all ei erine kuigi palju nitraatide hulgast kaera all (tabel 2 ja 3). Nitraatide hulk teise aasta mesika all ei ole suurem kui teiste taimede all (tabel 6). Võrreldes aga teise aasta mesikat mustkesaga (tabel 5) näeme, et mesika all on nitraate väga vähe.

Taimede alt kaovad nitraadid väga kiiresti. Berjozova ${ }^{\left[{ }^{10}\right]}$ seletab seda denitrifitseerijate mikroorganismide intensiivse arenemisega taime juurte

* Mulla nitraatide kogumisvõime määramiseks asetatakse muld termostaati $25^{\circ} \mathrm{C}$ temperatuuri. Sageli lisatakse veel kindel hulk lupiinijahu või $\left(\mathrm{NH}_{4}\right)_{2} \mathrm{SO}_{4}$. Teatud aja järele - umbes 15-30 päeva pärast (erinevate autorite järgi erineval ajal) - määratakse mullas nitraatide hulk. Suurem nitraatide kogumisvōime iseloomustab enamasti ka kōrgemat mullaviljakust. 
ümber. Goring ja Clark $\left[^{2}\right]$ leidsid, et nitrifikatsioon mullas taimede all ja ilma taimedeta on peaaegu ühesugune. Mineraalse lämmastiku kadu taimede alt aga ei saa seletada selle äratarvitamisega taimede poolt. Nende autorite andmetel toidavad juured mikroorganisme. Viimased kasutavad seejuures ära mullas leiduva mineraalse lämmastiku. Nitraatide kadumine taimede alt toimub ühelt poolt denitrifikatsiooni ja teiselt poolt mikroorganismide siduvuse tõttu. Tähtsam on teine viis, sest bakterite hulk mullas Goring'i ja Clark'i järgi on pöördvõrdelf̂ne nitraatide hulgaga.

Mesika all mullas intensiivistuvad mikrobioloogilised protsessid, mis on seotud lämmastikuühendite muutumisega. Viimaste mineralisatsioon mullas on seotud huumuse mineralisatsiooniga. Pole mingit alust oletada, et mesika all intensiivistub ainult mulla huumuse mineralisatsioon, sest nagu teada, suureneb liblikõieliste kasvatamisel orgaanilise aine kogus mullas. Alway' [7] järgi on liblikõieliste kasvatamine orgaanilise väetise asendajaks. Gussaki, Dimo ja Pankova [ $\left.{ }^{12}\right]$ andmetel suureneb mitmeaastaste heinte kasvatamisel huumuse- ja lämmastikusisaldus mullas. Seega võib pidada tõenäoliseks, et mesika all ei toimu ainult mulla orgaanilise aine intensiivsem mineralisatsioon, vaid ka süntees. Kuna samaaegselt mineralisatsiooniga intensiivistub ka mulla huumuse süntees mesika all, siis ei ole võimalik, et liikuva lämmastiku hulk suureneb mineraliseeruva orgaanilise aine arvel. Tõenäolisem on, et liikuva lämmastiku hulk suureneb õhulämmastikku siduvate bakterite intensiivsema tegevuse tōttu. Mesikapõllul võtavad ōhulämmastiku sidumisest osa nii mügarbakterid kui ka mullas vabalt elavad lämmastiku fiksaatorid, nende hulgas ka azotobakter. Kuna azotobakteri arenemine oleneb põhiliselt mullatingimustest - happesusest, nîskusest jne. - - mitte aga sellest, missugune taimeliik seal kasvab, on azotobakteri tegevus lämmastiku fiksaatorina mesika all mullas väikese tähtsusega. Azotobakterit sageli ei esinenudki analüüsimisele võetud muldades.

Kuigi vabaltelavad bakterid aitavad muuta ôhulämmastikku kättesaadavaks ka liblikõielistele taimedele, kuulub põhiline osa selles siiski mügarbakteritele. Mesikataimega kooselavate mügarbakterite laktiivsel kaasabil suureneb liikuva lämmastiku hulk.

Lipman [7], Virtanen [ $\left.{ }^{6}\right]$, Krassilnikov ja Korenjako $\left.{ }^{14}\right]$, Tamm ja Schendel $\left.{ }^{5}\right]$ ning paljud teised autorid on leidnud, et liblikõielised taimed eritavad juuresüsteemi kaudu mulda osa mügarbakterite poolt fikseeritud õhulämmastikku. Feodorovi ${ }^{\left[{ }^{18}\right]}$ arvates ei ole kinnitust leidnud selline väide, et liblikõielised taimed eritavad juurte kaudu mullasse ka lämmastikuühendeid, sest enamikku katseandmeid võib seletada ka teisest seisukohast. Feodorovi seisukohast ei kasuta liblikõielised mullas olevaid lämmastikuühendeid, vaid saavad lämmastikku ōhust mügarbakterite kaastegevusel. Seetõttu jääb teistele taimedele rohkem lämmastikuühendeid.

Russel $\left.{ }^{16}\right]$ märgib, et liblikõielised taimed eritavad mõnikord lämmastikuühendeid mulda, kuid tingimused, millistes see toimub, ei ole veel välja selgitatud. Nagu näitavad Tamm ja Schendel $\left.{ }^{5}\right]$, eritavad liblikõielised mulda lämmastikuühendeid ja ka kasutavad neid mullast. Märgitud fosfori abil on tehtud katseid, kus selgub, et märgitud fosfor võib üle minna talmede juureehitustest teiste taimede kudedesse [ ${ }^{17}$. Kuna fosfori ja teiste ainete eritumine ja neeldumine taime juurte poolt on üksteisega dünaamilises seoses, nagu näitavad Ahromeiko ja Sestakova $\left[{ }^{9}\right]$, siis ei ole otstarbekohane eitada sama ka lämmastiku suhtes.

Juurte küljest äralangevad rakulised elemendid, mis lagunevad mullas, etendavad väga väikest osa lämmastikubilansis liblikõieliste kasvu ajal [5]. Lämmastiku hulk suureneb mullas peamiselt liblikõieliste juureeritiste arvel. Need juureeritised pole kasutatavad teiste taimede poolt, vaid need 
neelab kõigepealt risosfääri mikrofloora. Selline seletus ühtib peaaegu kõigi faktidega ja selgitab, miks sageli ei avastata juureeritisi.

Seega mesika mõju uurimine mulla mikrofloorale, samuti katteviljasaagile aitab lahendada küsimust mullaviljakuse muutustest mesika kasvu ajal. Mullaviljakuse seisukohalt on suur tähtsus mitte üksi haljasväetiseks, vaid ka teisteks otstarveteks (söödaks, seemneks jne.) kasvatataval mesikal. Seega võib ühineda Meleško [ ${ }^{16}$ ] seisukohaga, et mesika kasvatamine, olenemata otstarbest, on tähtis mullaviljakuse tõstmise aspektist.

\section{KIRJANDUS}

1. Eesti NSV Teaduste Akadeemia Pōllumajanduse Instituudi Kuusiku filiaali teadusliku töö aruanded 1946-1950.

2. Goring, C. A. J. and Clark, F. E., Influence of Crop Growth on Mineralisation of Nitrogen in the Soil. Soil Science Society of America Proceedings, V 13, 1949, $261-266$.

3. Haller, E., Valge mesika kasvatamine ja kasutamine. Tallinn, 1951.

4. Ka il a, A., Influence of Legumes upon Soil Fertility. Suomalaisen Tiedeakatemian Toimituksia, Sarja A II, Chemica 42, Helsinki 1952.

5. T a mm, E. und Schendel, U., Zur Frage der Stickstoffabgabe und -aufnahme durch Leguminosenwurzeln während des Wachstums. Zeitschrift für Pflanzenernährung, Düngung u. Bodenkunde, Band 64 (109), Heft 2, 1954, 147-153.

6. Virt a nen, A. J., Nitrogen Fixation Compounds from the Root Nodules. Annals of the Agricultural College of Sweden, V 5, 1938, 429-452.

7. W a ksman, S. A., Soil Microbiology. New York, 1952.

8. А фан асье в а А. А., Микробиологические процессы в почве под многолетними травами. Агробиология, 1950, 5, стр. 60.

9. Ахромей ко А. И. и Ш ест аков а В. А., Роль ризосферных микроорганизмов в питании растений. Меченые атомы в исследованиях питания растений и применения удобрений. Изд. АН СССР. Москва, 1955.

10. Берез ов а Е. Ф., Роль микроорганизмов в питании растений в свете передовой агробиологической науки. Советская апрономия, 1950, 11, стр. 77.

11. Бе рез ов а Е. Ф., Ш а ин С. С., Р емп е Е. Х., Микрофлора корневой системы многолетних трав в чистом посеве и травосмеси. Труды Всесоюзного научноисследовательского института сельскохозяйственной микробиологин, т. XIII, 1953.

12. Гуссак В. Б., Димо В. Н., П анкова Н. А., Влияние травопольного севооборота на некоторые свойства дерново-подзолистых почв Московской области. Почвоведение, 1950, 12, стр. 746.

13. К расильников Н. А., Микроорганизмы и плодородие почвы в свете учения В. Р. Вильямса. Агробнология, 1952, стр. 57.

14. К ра сильников Н. А. и К ореняко А. И., Влияние клубеньковых бактерии на азотофиксащию клевера. Микробиология, т. ХV, вып. 4, 1946.

15. М ел е шко Н. А., Донник. Сельхозиздат, Москва, 1934.

16. Р ассел Э., Почвенные условия и рост растений. Издательство иностранной литературы, Москва, 1955.

17. Соколов А. В., Использование радиоактивного фосфора в агрохимических и почвенных исследованиях. Вестник АН СССР, 1953, 9, стр. 28-34.

18. Фед оро в М. В., Биологическая фиксация азота атмосферы. Сельхозгиз, Москва, 1952.

Eesti Maaviljeluse ja Maaparanduse Teadusliku Uurimise Instituut

Saabus toimetusse

4. I 1957 


\title{
О МИКРОБИОЛОГИЧЕСКИХ ПРОЦЕССАХ В ПОЧВЕ ПРИ ВЫРАЩИВАНИИ БЕЛОГО ДОННИКА
}

\author{
В. Р. Ластинг
}

Резюме

Белый донник широко используется в Эстонской ССР в качестве зеленого удобрения и кормовой культуры. В то же время в литературе имеются главным образом эмпирические данные, свидетельствующие о положительном влиянии донника на плодородие почвы. В связи с этим большой интерес представляет изучение микробиологических процессов, происходящих в почве при выращивании белого донника.

Результаты исследований, проведенных в основном в Қуузику в 1953-1955 гг., показали, что растущий донннк активизирует микробиологические процессы почвы. Так, количество аммонифицирующих бактерий под донником первого года жизни воз. растает в 1,5-2 раза по сравнению с участками, где выращивалась одна покровная культура. В 2-4 раза увеличивается количество целлюлозоразлагающих бактерий и до десяти раз - содержание нитрифицирующих бактерий. При этом следует отметить, что разница между вариантами проявляется наиболее четко лишь во второй половине лета, когда донник начинает развиваться более интенсивно.

Незначительно изменялось количество грибов. По данным наших опытов, донник почти не оказал никакого влияния на развитие азотобактера, маслянокислых и денитрифицирующих бактерий. Донник второго года жизни оказывает такое же влияние на деятельность почвенной микрофлоры, как и донник первого года. Под донником второго года также увеличивается количество аммонифицирующих, нитрифицирующих и целлюлозоразлагающих бактерий. Сравнительное исследование микробнологических процессов под донником второго года жизни и черным паром показало, что содержание аммонифицирующих бактерий в отличие от нитрифицирующих и целлюлозоразлагающих выше в почве, находящейся под паром. Интенсивная аммонификация в этой почве приводит к накоплению нитратов, в то время как под донником запас нитратов минимален.

Эти данные позволяют полагать, что в черном пару, пю-видимому, доминируют процессы минерализации почвенного органического вещества, в то время как под донником, наряду с минерализацией, протекают интенсивно также н процессы синтеза новых органических веществ. Подсев донника не приводит к снижению урожая покровной культуры, а подсев его по фону фосфорных и калийных удобрений (без азота) даже повышает. Повышение урожая покровной культуры, как и последующих культур. несомненно обусловлено увеличением количества. подвижных азотистых соединений, возникающих в почве под донником в результате активной микробиологической деятельности.

Главная роль в накоплении биологического азота под донником принадлежит клубеньковым бактериям. Деятельность свободноживущих азотфиксирующих микроорганизмов и, в частности, азотобактера выражена слабее.

Таким образом, донник (аналогично другим многолетним бобовым культурам) способствует развитию в своей ризосфере весьма важных групп микроорганизмов, повышая при этом биологическую активность почвы. Поэтому выращивание донника (на корм, семена или зеленое удобрение) является важным фактором повышения плодородия и, несомненно, имеет большое значение в сельскохозяйственном производстве.

\section{Эстонский научно-исследовательский институт земледелия и мелиорации \\ Поступила в редакцию 4 I 1957}

\section{DIE MIKROBIOLOGISCHEN PROZESSE IM BODEN BEI DER KULTIVIERUNG DES WEISSEN HONIGKLEES}

\author{
V. Lasting
}

\section{Zusammenfassung}

Der weisse Honigklee wird in der Estnischen SSR umfangreich zu Zwecken der Gründüngung und als Futterkultur angebaut.

In der Literatur sind bisher meist empirische Angaben veröffentlicht worden, die vom günstigen Einfluss des Honigklees auf die Bodenfruchtbarkeit zeugen. Die von uns angestellten Versuche gaben nun den Nachweis, dass der im Wachstum begriffene Honigklee die im Boden vor sich gehenden mikrobiologischen Prozesse aktivisiert. So stieg die Menge der ammonifizierenden Bakterien in der Rizosphäre des Honigklees im ersten Jahr seines Wachstums 1,5-2mal. Die Menge der zellulosezersetzenden Bakte- 
rien stieg 2-4mal, die der nitrifizierenden bis $10 \mathrm{mal}$. Es ist $\mathrm{zu}$ vermerken, dass der Unterschied in der Zahl der Bakterien bei den Varianten erst in der zweiten Hälfte des Sommers ganz deutlich zum Vorschein kommt, nachdem der Honigklee ins intensivere Stadium des Wachstums getreten ist.

Die Menge der Pilze im Boden, wo Honigklee angebaut wurde, erfuhr bloss geringe Veränderungen. Der Honigklee übte auf die Entwicklung des Azotobakters, der Buttersäurebakterien und der denitrifizierenden Bakterien gar keine Wirkung aus. Im zweiten Jahr seines Wachstums beeinflusst der Honigklee die im Boden vor sich gehenden mikrobiologischen Prozesse auf dieselbe Weise wie im ersten Jahr: es steigert sich im zweiten Jahr gleichfalls die Menge der ammonifizierenden, der nitrifizierenden und der zellulosezersetzenden Bakterien.

Eine vergleichende Betrachtung der mikrobiologischen Prozesse im Boden unter dem Honigklee und in der Schwarzbrache hat ergeben, dass der Gehalt an ammonifizierenden Bakterien (im Gegensatz zu den nitrifizierenden und den zellulosezersetzenden) im aufgepflügten Boden grösser ist. Infolge der intensiveren Ammonifikation werden in der Schwarzbrache auch viel Nitrate angesammelt, während ihre Menge unter dem Honigklee sehr gering ist. Diese Tatsachen lassen schliessen, dass in der Schwarzbrache Mineralisationsprozesse der organischen Stoffe überwiegen, in der Rizosphäre des Honigklees dagegen die Mineralisation parallel verläuft mit intensiven Prozessen, die mit der Synthese neuer organischer Stoffe im Boden verbunden sind.

Durch die Honigklee-Untersaat wird der Ertrag der Uberfruchtkulturen nicht vermindert, sondern bei Zuführung von Kali-Phosphatdüngemitteln (ohne Stickstoffdüngung) sogar vergrössert. Der steigende Ertrag der Uberfruchtkulturen und der darauf folgenden Kulturen ist bedingt durch die Zunahme der Menge der Stickstoffverbindungen; es ist dies wiederum Folge der aktiveren mikrobiologischen Prozesse im Boden, die der Honigklee hervorruft.

Bei der Anhäufung biologischen Stickstoffes fällt die wichtigste Rolle den Knöllchenbakterien zu. Die Wirkung der im Boden frei lebenden Stickstoff-Fixatoren, namentlich des Azotobakters, ist von geringer Bedeutung.

Der Honigklee (wie auch andere mehrjährige Schmetterlingsblüter) fördert also in seiner Rizosphäre die Entwicklung wichtiger Gruppen von Mikroorganismen, wobei er die biologische Aktivität des Bodens steigert. Demgemäss ist sein Anbau vom Standpunkt der grösseren Fruchtbarkeit unserer Felder von grosser Bedeutung.

Institut für Ackerbau und Melioration 